\title{
Adhesion GPCRs are widely expressed throughout the subsections of the gastrointestinal tract
}

\author{
Luca Badiali ${ }^{1,2}$, Jonathan Cedernaes ${ }^{1}$, Pawel K Olszewski ${ }^{1,3}$, Olof Nylander ${ }^{1}$, Anna V Vergoni ${ }^{2}$ and Helgi B Schiöth ${ }^{1 *}$
}

\begin{abstract}
Background: G protein-coupled receptors (GPCRs) represent one of the largest families of transmembrane receptors and the most common drug target. The Adhesion subfamily is the second largest one of GPCRs and its several members are known to mediate neural development and immune system functioning through cell-cell and cell-matrix interactions. The distribution of these receptors has not been characterized in detail in the gastrointestinal (Gl) tract. Here we present the first comprehensive anatomical profiling of mRNA expression of all 30 Adhesion GPCRs in the rat $\mathrm{Gl}$ tract divided into twelve subsegments.
\end{abstract}

Methods: Using RT-qPCR, we studied the expression of Adhesion GPCRs in the esophagus, the corpus and antrum of the stomach, the proximal and distal parts of the duodenum, ileum, jejunum and colon, and the cecum.

Results: We found that twenty-one Adhesion GPCRs (70\%) had a widespread (expressed in five or more segments) or ubiquitous (expressed in eleven or more segments) distribution, seven (23\%) were restricted to a few segments of the Gl tract and two were not expressed in any segment. Most notably, almost all Group III members were ubiquitously expressed, while the restricted expression was characteristic for the majority of group VII members, hinting at more specific/localized roles for some of these receptors.

Conclusions: Overall, the distribution of Adhesion GPCRs points to their important role in Gl tract functioning and defines them as a potentially crucial target for pharmacological interventions.

\section{Background}

The superfamily of G protein-coupled receptors (GPCRs) is one of the largest families of membrane bound proteins in the human genome [1] comprising about 800 members. Being involved in a high number of physiological functions, including development, neurotransmission, metabolism, reproduction, immune responses, and behavior, GPCRs act as receptors for a great number of different signals, both endogenous - amines, peptides, proteins, lipids, nucleotides, neurotransmitters - and sensory, as organic odorants, pheromones, tastes and photons. According to the phylogenetic analysis of the entire human GPCR repertoire, five subfamilies make up the GRAFS classification system: Glutamate, Rhodopsin, Adhesion, Frizzled/ Taste2 and Secretin [2]. The phylogenetic grouping of

\footnotetext{
* Correspondence: helgi.schioth@neuro.uu.se

${ }^{1}$ Department of Neuroscience, Uppsala University, BMC, Uppsala SE 75124, Sweden

Full list of author information is available at the end of the article
}

Adhesion GPCRs, based on the 7TM regions, revealed that there are seven groups [3].

GPCRs are characterized by having seven $\alpha$-helices that span the plasma membrane and form a receptor with a binding cavity for a ligand; the extracellular segment may also be able to bind a ligand. The main feature of the Adhesion family is the long $\mathrm{N}$ terminus with complex domain architecture which is thought to be highly glycosylated and form a rigid structure in the outer part of the protein. This extracellular portion contains the GPCR proteolytic site (GPS) and several various domains that can also be found in other proteins such as lectin, epidermal growth factor, olfactomedin, immunoglobulin, thrombospondin and cadherin domains [3]. The GPS domain is referred to as an intracellular cleavage motif, pivotal for the protein transport from the endoplasmic reticulum to the membrane [4], while several other $\mathrm{N}$ terminal domains play important roles in the receptorligand binding as well as cell-to-cell and cell-to-matrix adhesion [5]. Distinguishing themselves even more from

\section{Biomed Central}


other GPCRs, Adhesion GPCRs are genomically complex, each receptor having many isoforms [6], with multiple alternatively-spliceable introns and large genomic sizes, which makes them difficult to study [7]. Only a few members of Adhesion GPCRs have been demonstrated to interact with $\mathrm{G}$ proteins $[8,9]$.

Beyond its evident role in digestion and adsorption, the gastrointestinal (GI) tract is involved in a variety of other physiological functions, such as endo- and exocrine secretion and immune responses [10-12]. Its autonomous neuronal network, referred to as the enteric nervous system or ENS, is also intimately linked with the brain in the brain-gut axis important for, among others, food intake regulation $[13,14]$. GPCRs in the GI tract are known to be involved in nutrient balancing [15-17] and regulation of the immune system $[18,19]$. In some cases their gross expression patterns in the GI tract have been established, but more subtle proximodistal variations in expression and their biological functions have yet to be determined [20]. Furthermore, dysfunction of GPCRs is already known to contribute to certain diseases affecting the GI tract. For example, GPR49 overexpression has been related to increased incidence of human colon primary tumors [21], whereas overexpression of the Adhesion GPCR CD97 has been correlated to colorectal cancer [22], rectal adenocarcinoma recurrence and metastasis [23], and gastric carcinoma [24].

Though about $85 \%$ of Adhesion GPCRs are still orphans or lack biological characterization (details about known functions are provided in [6]), EMR receptors have been shown to be involved in immune responses [25]: Crohn's disease and ulcerative colitis are two of the main inflammatory bowel diseases affecting the GI tract, and there is a growing body of evidence indicating that the onset of these pathologies may be related to an immune system deregulation by the ENS or gut microbiota $[11,12]$. The characterization of immunologically important Adhesion GPCRs in the GI tract may therefore lead to a greater understanding of these pathological conditions. Profiling of the entire GI tract, accounting for intra-regional differences is important since proximaldistal part of GI tract's anatomical regions can serve different roles or be selectively affected by diseases; e.g. bile acids and vitamin B12 adsorption occur in the distal ileum, Barrett's disease affects the distal esophagus [26], and gastric cancer occurs either proximally or distally [27]. Likewise, Crohn's disease more frequently affects the terminal ileum [28]. Knowledge of the proximodistal expression pattern may therefore indirectly facilitate pinpointing the function of Adhesion GPCR orphans.

We present here the first complete analysis of mRNA expression of all members of the Adhesion GPCRs subfamily throughout the entire rat GI tract, which was divided into twelve subsegments (as described previously
[29]). Using RT-qPCR with a validated range of housekeeping genes, we studied the expression in the esophagus, the corpus and the antrum of the stomach, the proximal and distal parts of the duodenum, jejunum, ileum and colon, and in the cecum.

\section{Methods}

\section{Animal handling and tissue isolation}

Three male Dark Agouti rats (Scanbur AB, Sweden) weighing approximately 200 grams, were kept under constant conditions $\left(12 \mathrm{~h}\right.$ dark/light cycle) at $21^{\circ} \mathrm{C}$. The animals were fasted overnight but had free access to water before carrying out the experiment. The following morning the animals were intraperitoneally anesthetized with Na-5-ethyl-1-(1'-methyl-propyl)-2-thiobarbituric acid (Inactin ${ }^{\circledR} ; 125 \mathrm{mg} / \mathrm{kg} \mathrm{b}$. wt). Body temperature was maintained at $37.5 \pm 0.5^{\circ} \mathrm{C}$ through a temperature regulator controlling a heating pad. Thereafter, a tracheotomy was performed and a cannula (PE-200) was inserted to guarantee free airways. Following a midline incision to open the abdominal cavity, the following structures, about 5 to $10 \mathrm{~mm}$ in length, were localized and dissected (Figure 1): Distal esophagus (a few $\mathrm{mm}$ from the stomach); corpus of the stomach; antrum of the stomach; proximal $(1 \mathrm{~mm}$ from the pylorus) and distal duodenum $(4 \mathrm{~cm}$ from the pylorus); proximal ( $9 \mathrm{~cm}$ from the pylorus) and distal jejunum (19 $\mathrm{cm}$ from the pylorus); proximal $(29 \mathrm{~cm}$ from pylorus) and distal ileum $(2.5 \mathrm{~cm}$ from the ileocecal valve); cecum; proximal (5 $\mathrm{cm}$ from ileocecal valve) and distal colon (12 cm from the ileocecal valve). The whole GI tract wall was isolated for the RT-qPCR analysis.

After the operation, an intravenous bolus injection of a saturated $\mathrm{KCl}$ solution was used to euthanize the animals. All animal procedures followed the regulations and policies outlined by the Swedish Animal Protection Act and were approved by the Uppsala Ethic Committee.

\section{RNA isolation and CDNA synthesis}

RNA isolation and cDNA synthesis were performed as previously reported [30]. Briefly, tissue samples were homogenized by sonication in the TRIzol reagent (Invitrogen, Sweden) using a Branson sonifier. Chloroform was added to the homogenate and centrifuged at $12000 \mathrm{~g}$ at $4^{\circ} \mathrm{C}$ for 15 minutes. The aqueous phase was collected and RNA precipitated with isopropanol. The pellets were washed with $75 \%$ ethanol, air dried and dissolved in RNAse-free water. The DNAse treatment was performed to remove DNA contamination: DNAse I (Roche Diagnostics, Sweden) was added to the samples and incubated at $37^{\circ} \mathrm{C}$ for $4 \mathrm{~h}$, followed by inactivation by heating to $75^{\circ} \mathrm{C}$ for 15 minutes. Absence of DNA contamination in the RNA samples was confirmed by PCR. Nanodrop ${ }^{\circledR}$ ND-1000 Spectophotometer (NanoDrop Technologies, Delaware, USA) was used to determine RNA concentration. 


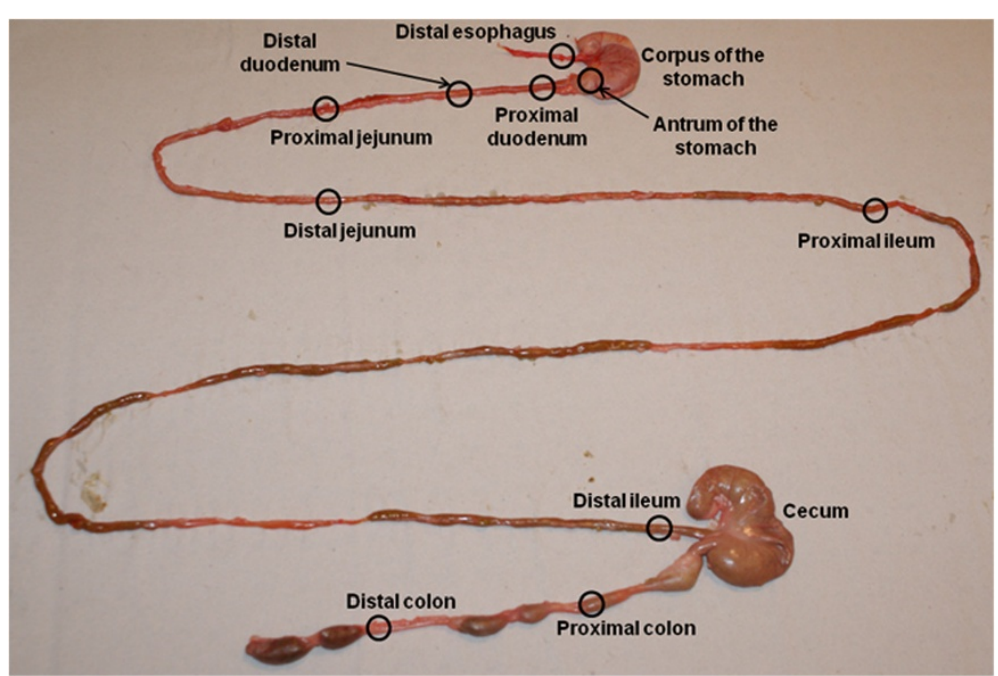

Figure $1 \mathrm{Gl}$ sectioning approximately indicating the different sections of the rat $\mathrm{Gl}$ tract used for analysis. The Gl tract was divided into twelve segments: the esophagus, the corpus and the antrum of the stomach, the proximal and distal parts of the duodenum, ileum, jejunum and colon, and the cecum.

Thereafter, cDNA was synthesized by priming with random hexameres and MMLV reverse transcriptase (GE Healthcare, Sweden). PCR was performed to confirm cDNA synthesis. An equal amount of the total cDNA from each of the three rats was pooled, and the pooled solution was used as the template material for RT-qPCR.

\section{Primer design}

Sequences for rat housekeeping genes and all known Adhesion GPCR gene sequences were downloaded from the GenBank. All primers were designed using Beacon Primer Design 7.0 (Premier Biosoft, USA) and positioned within TM regions of the Adhesion GPCRs. The primer sequences for rat Adhesion GPCRs and housekeeping genes are provided in additional material (see Additional file 1).

\section{Quantitative real-time PCR}

The RT-qPCR was performed using a MyiQ thermal cycler (Bio-Rad Laboratories, Sweden). Each RT-qPCR reaction, with a total volume of $20 \mu \mathrm{l}$, contained cDNA synthesized from $25 \mathrm{ng}$ of total RNA, $0.25 \mathrm{pmol} / \mu \mathrm{l}$ of each primer, $20 \mathrm{mM}$ Tris- $\mathrm{HCl}(\mathrm{pH} 8.4), 50 \mathrm{mM} \mathrm{KCl}$, $4 \mathrm{mM} \mathrm{MgCl} 2,0.2 \mathrm{mM}$ NTP, SYBR Green (1:50000) (Invitrogen, USA) and $0.02 \mathrm{U} / \mu \mathrm{l}$ Taq DNA polymerase (Biotools, Spain). The reaction conditions were the following: initial denaturation at $95^{\circ} \mathrm{C}$ for $4 \mathrm{~min}$, succeeded by 40 cycles at $95^{\circ} \mathrm{C}$ for $15 \mathrm{~s}, 55-62^{\circ} \mathrm{C}$ for $30 \mathrm{~s}$ (optimal annealing temperature) and $72^{\circ} \mathrm{C}$ for $30 \mathrm{~s}$. This was followed by 81 cycles at $55^{\circ} \mathrm{C}$ for $10 \mathrm{~s}$ (increased by $0.5^{\circ} \mathrm{C}$ per cycle). All real-time PCR experiments were run in triplicates. A negative control for each primer pair and a positive control with $25 \mathrm{ng}$ of rat genomic DNA was included on each plate.

\section{Data analysis and relative expression calculations}

Bio-Rad iQ5 software v2.0 software (Bio-Rad Laboratories, Sweden) was used to process RT-qPCR data and obtain threshold cycle $(\mathrm{Ct})$ values. Melting curves were analyzed to assure that only one product with the expected melting point was amplified and that this was separate from the negative control. LinRegPCR was used to calculate PCR efficiencies for each sample and Grubbs' test (GraphPad, USA) was applied to exclude any outliers when calculating the average PCR efficiency for each primer pair. The delta Ct method [31] was used to convert $\mathrm{Ct}$ values into relative quantities with the standard deviation, and the highest expression was normalized to 1 . The GeNorm software [32] was used with results from the five most stable housekeeping genes to calculate normalization factors for each tissue to compensate for differences in cDNA quantity. Subsequently, the normalized quantities were calculated and maximum expression was set to 1: all relative expression values are shown as fold decrease with respect to the detected maximum expression (see Additional file 2).

\section{Results}

The rat Adhesion GPCR gene sequences were downloaded from GenBank (see Additional file 1) and 7TM regions were identified with the Conserved Domain Database [33]. We analyzed the expression of 30 Adhesion GPCR family members in the rat GI tract. The gut was divided into twelve different segments proceeding from the esophagus to the colon and each tissue was 
isolated and used for RNA extraction and cDNA synthesis. The expression values of five housekeeping genes (Histone protein 3b, $\beta$-tubulin, $\beta$-actin, succinate dehydrogenase complex, subunit $A$ and cyclophilin) were used to calculate normalization factors for rat cDNA. Each reaction was run in triplicate and with a positive control (genomic DNA) to confirm the validity of the amplification process; relative expression values for rat Adhesion GPCRs are displayed as a fold decrease relative to the detected maximum expression, arbitrarily set at 1 (see Additional file 2).

A total of twelve GPCRs (40\%) were found to be ubiquitous along the GI system (expressed in at least eleven segments - Figure 2), nine GPCRs (30\%) had widespread expression (detected in at least five segments - Figure 3), seven GPCRs (23\%) had restricted expression (transcript found in no more than four segments - Figure 4) and two GPCRs were not detected in any segments. The ubiquitously expressed genes (Figure 2) consisted of two members from Group II, namely GPR56 and GPR97 (although neither was expressed in the esophagus), all but one $(E M R 4)$ of the members from Group III (LEC1, LEC2, LEC3, ETL, EMR1, CD97), two members from Group IV (GPR124 and GPR125; the third member GPR123 could not be detected in any segment), GPR133 from Group V, and GPR116 from Group VII.

Among genes with widespread expression (Figure 3), $B A I 2$ and BAI3 displayed a very similar pattern, being detected in the antrum of the stomach and the proximal part of the duodenum, and from the distal jejunum to

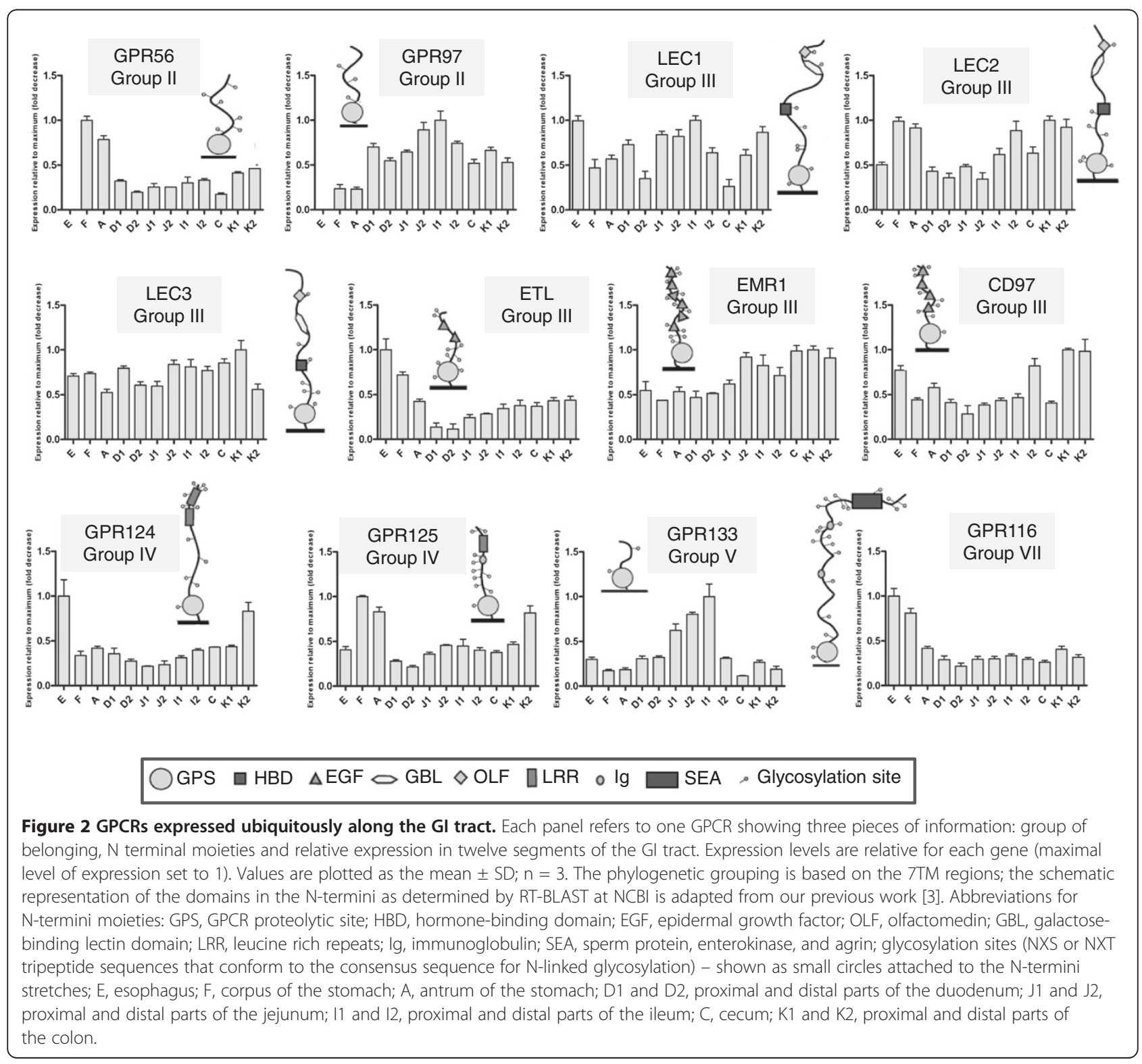




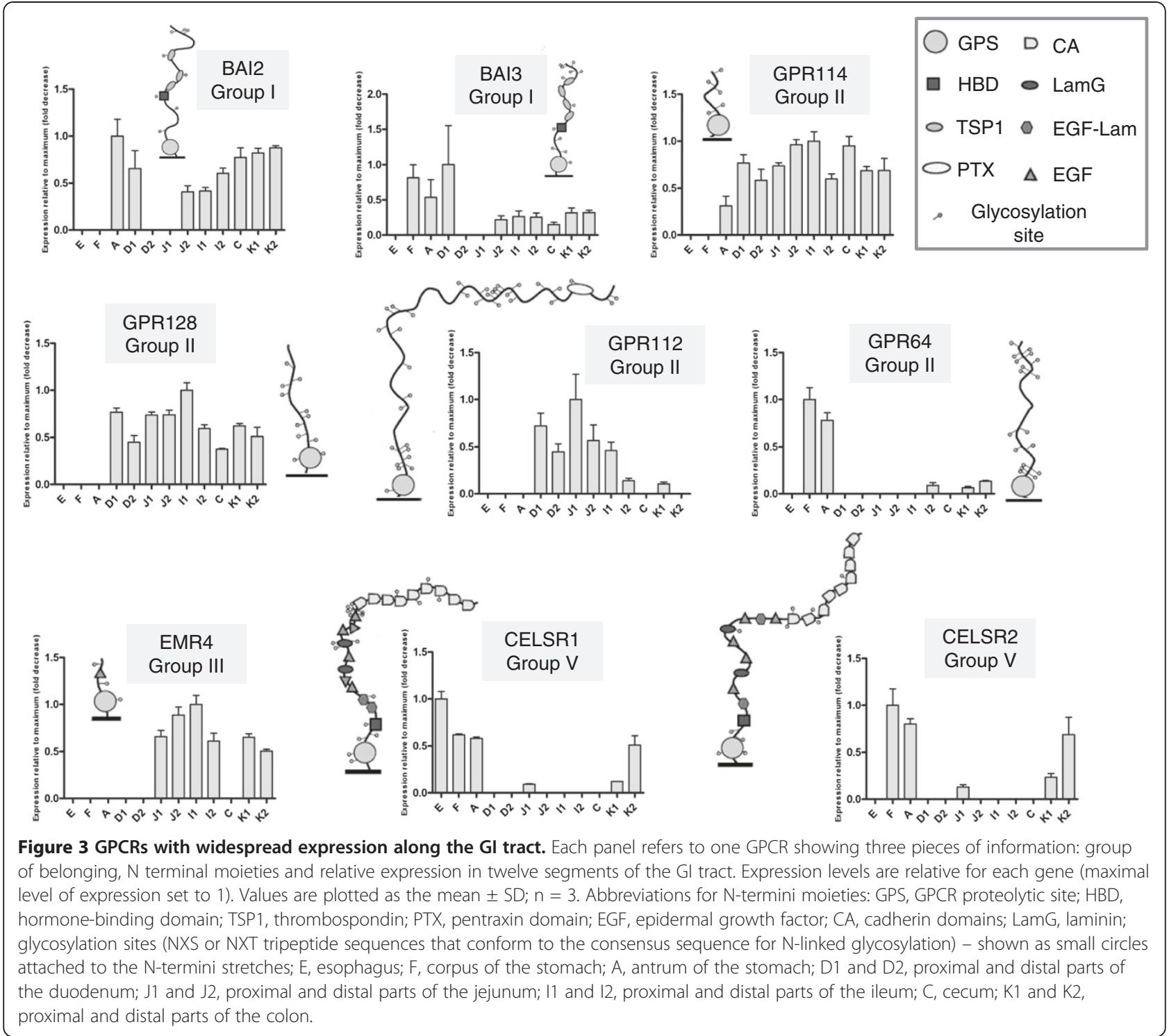

the colon. In comparison, BAII had limited expression, only being detectable in the distal ileum and colon. GPR114 was found throughout the entire GI tract except for the esophagus and fundus of the stomach, while GPR128 was expressed in the whole intestine, but not in the stomach or esophagus. GPR112 was found in the duodenum, jejunum, ileum and proximal colon. GPR64 was expressed only in the stomach and, to a lesser extent, in the distal ileum and colon. CELSR1 and CELSR2, members of Group V, displayed a very similar pattern, being expressed in the stomach, colon and proximal jejunum, while CELSR1 was also found in the esophagus. No expression of CELSR3 could be detected. EMR4 expression was restricted to the jejunum, ileum and colon. Out of the nine widespread Adhesion GPCRs, as many as four belong to Group II.
In total, seven genes had restricted expression (Figure 4), including the aforementioned BAI1. Two genes were members of Group II: VLGR1, with increasing expression from the jejunum to the proximal part of ileum, and GPR126, with isolated expression in the ileum and colon. An expression pattern similar to that of the latter gene was also observed for GPR110, belonging to Group VII, while from the same group, GPR111 and GPR115 were only expressed in the esophagus, and GPR113 expression was detected at a low level only in the proximal colon. Out of the seven genes with restricted expression, the majority (4 out of 7) thus belonged to Group VII.

\section{Discussion}

In this paper, we present the first comprehensive chart of the mRNA expression of all 30 Adhesion GPCRs in the 


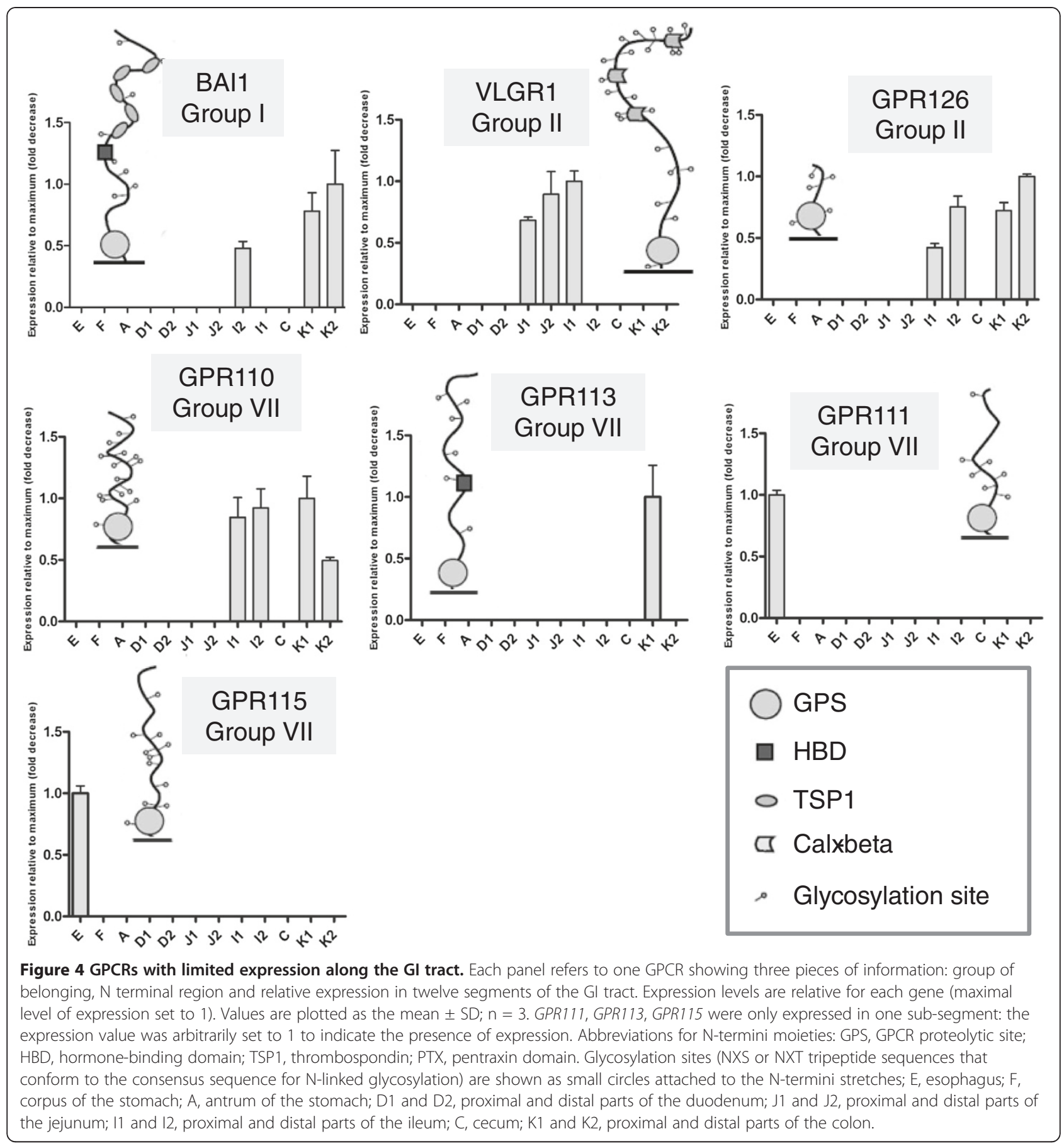

rat GI tract. We find that the majority of the GPCRs are expressed ubiquitously throughout the GI tract, highlighting their importance for GI tract physiology. At the same time, the restricted expression patterns of seven GPCRs suggest that these receptors may have specific functions in these parts of the GI tract and they in particular may constitute potential therapeutic targets. While two other studies have mapped GPCRs expression in the mouse gut $[34,35]$ as well as one study that mapped the Adhesion GPCRs expression distribution in the mouse and rat [36], in none of these studies has the GI system been divided into so many segments, using both proximal and distal subsegments of several GI tract regions. Based on our results we found that the Adhesion GPCRs could be divided into three categories: genes ubiquitously expressed, genes with widespread expression, and genes with restricted/ specific expression. 


\section{Genes with ubiquitous expression}

Twelve GPCRs (namely GPR56, GPR97, LEC1, LEC2, LEC3, ETL, EMR1, CD97, GPR124, GPR125, GPR133 and GPR116) were detected in at least eleven segments along the GI tract (Figure 2). Being ubiquitously expressed, these genes may play important roles for normal GI tract functioning. Intriguingly though, most of these receptors still have no known functions. Among the few de-orphanized GPCRs, GPR56 is known to be involved in the development of the testis [37], and CNS [38,39]. Similarly, GPR56 might be involved in the development of the GI tract. Furthermore, overexpression of GPR56 has been reported in esophageal squamous cells carcinomas (EECCs) and dysplastic tissues contrary to adjacent nonmalignant esophageal tissue [40]. As we found no esophageal expression in wild type animals, but high gastric (especially fundus) expression, our results lends further support to the conclusion by Sud et al. that GPR56 is an interesting candidate as an early diagnostic marker in esophageal cancer.

CD55 and chondroitin sulphate have been described as ligands for CD97 leading to leukocyte activation [41]: lack of CD55 and CD97 resulted in decreased arthritis in mouse experimental models of rheumatoid arthritis [42]. CD97 has also been implicated in the initiation and establishment of inflammatory processes, e.g. in multiple sclerosis [43]. Outside cells of the immune system, CD97 is also expressed in smooth muscle cells [44,45]. Since we detected the transcript throughout the whole GI tract, probably also in associated immune cells, we suggest CD97 might constitute a target in inflammatory bowel diseases, in particular Crohn's disease that is able to affect any region of the GI tract [46]. Interestingly, all but one of the members of the group III members were ubiquitously expressed, which could imply that this group of Adhesion GPCRs is of particular importance for GI tract functioning.

\section{Genes with widespread expression}

Nine genes (BAI2, BAI3, GPR114, GPR128, GPR112, GPR64, EMR4, CELSR1 and CELSR2) were found to have widespread expression, that is, they were detected in more than five segments (Figure 3). BAI2 and BAI3, belonging to the family of brain angiogenesis inhibitor (BAI), displayed very similar expression patterns. Therefore, they might serve similar roles, such as being involved in angiogenesis in the GI tract, which is pivotal in ischaemia and tumorigenesis, and which has recently been shown to be of importance for the development and perpetuation of IBD [47,48]. GPR64 is known to interfere with fluid re-adsorption [49] and our results showed high expression of the GPR64 transcript in the stomach but not in adjacent segments. We therefore speculate that GPR64 might be important for water homeostasis during the first digestive process in the stomach where water, together with mucus, $\mathrm{HCl}$ and pepsinogen, are secreted.

From the CELSR family, CELSR2 and CELSR3 are known to be distributed mainly in CNS and to regulate neural development [50]. In contrast, CELSR1 has been described in lungs, involved in spatial development and branching morphogenesis [51]. Given that CELSR1 and CELSR2 had such limited but very similar expression in the GI tract, we hypothesize that these two genes might control the reciprocal signaling interactions between the epithelium and mesenchyme during morphogenesis of gastric epithelia and their expression is maintained also in the adult stage. GPR112 has been reported in the dominant neuroendocrine cells of the GI tract, the enterochromaffin (EC) cells, in the normal mucosa of the human ileum, and also as a potential target for GI neuroendocrine carcinomas [52]. We detected its transcript in the duodenum - where EC cells display the highest expression [53] - jejunum, ileum and proximal colon: our finding is in good agreement with the work of Ito et al. [35]. GPR112 could be involved in serotonin release or participate in the nutrient sensing functions of EC cells [54].

\section{Genes with restricted expression}

Seven GPCRs (BAI1, VLGR1, GPR126, GPR110, GPR113, GPR111 and GPR115) were found to be expressed in fewer than five segments (Figure 4), each showing highly specific and varying expression patterns. BAI1 is known to be involved in angiogenesis, tumor formation [55] and host responses to Gram-negative infections [56], which include severe ICU-acquired infections [57,58]. Given the restricted expression in the colon and ileum, this receptor may play a role in tumor development in the intestine and in defense mechanisms against Gramnegative bacteria in the lower GI tract. GPR126 has been reported to play an essential role for peripheral nerve development and myelination in mammals [59]; its limited expression in the ileum and colon could suggest an involvement in myelination of neurons of the myenteric plexuses crucial for GI motility, or submucosal plexuses, which regulate luminal and epithelial cell function. Mutations on VLGR1 are known to underlie human Usher syndrome type II [60]. The complex extracellular domain of the VLGR1 receptor, with a Calx- $\beta$ cation binding motif, has led to a suggested role in the sensing of $\mathrm{Ca}^{2+}$ [61]. Given that VLGR1 expression was restricted to the jejunum and proximal ileum, one might hypothesize that VLGR1 participates in $\mathrm{Ca}^{2+}$-sensing in the small intestine. GPR110 has been recently shown to be an oncogene in murine $\mathrm{T}$ lymphomas and a marker for lung and prostate cancer [62]. The receptor is orphan, and since the expression was restricted to the ileum and 
colon, GPR110 could potentially play a role in sensing nutrients or in malignancies, such as Coeliac diseaseassociated $\mathrm{T}$ lymphomas [63] or cancer of the small or large intestine.

There were consistent differences in the expression between the proximal and distal part of the same segment for a given gene, as shown in Figure 5, which highlights GPCRs highly expressed in specific subsegments of the GI tract. For example, VLGR1 had its highest expression in the proximal ileum, but it was not detected in the distal segment (Figure 4). This observation is in accordance with our previous work [29], describing notable proximodistal differences in solute carrier profiling in the GI tract. Our results therefore further support the rationale of analyzing each segment not as a homogenous

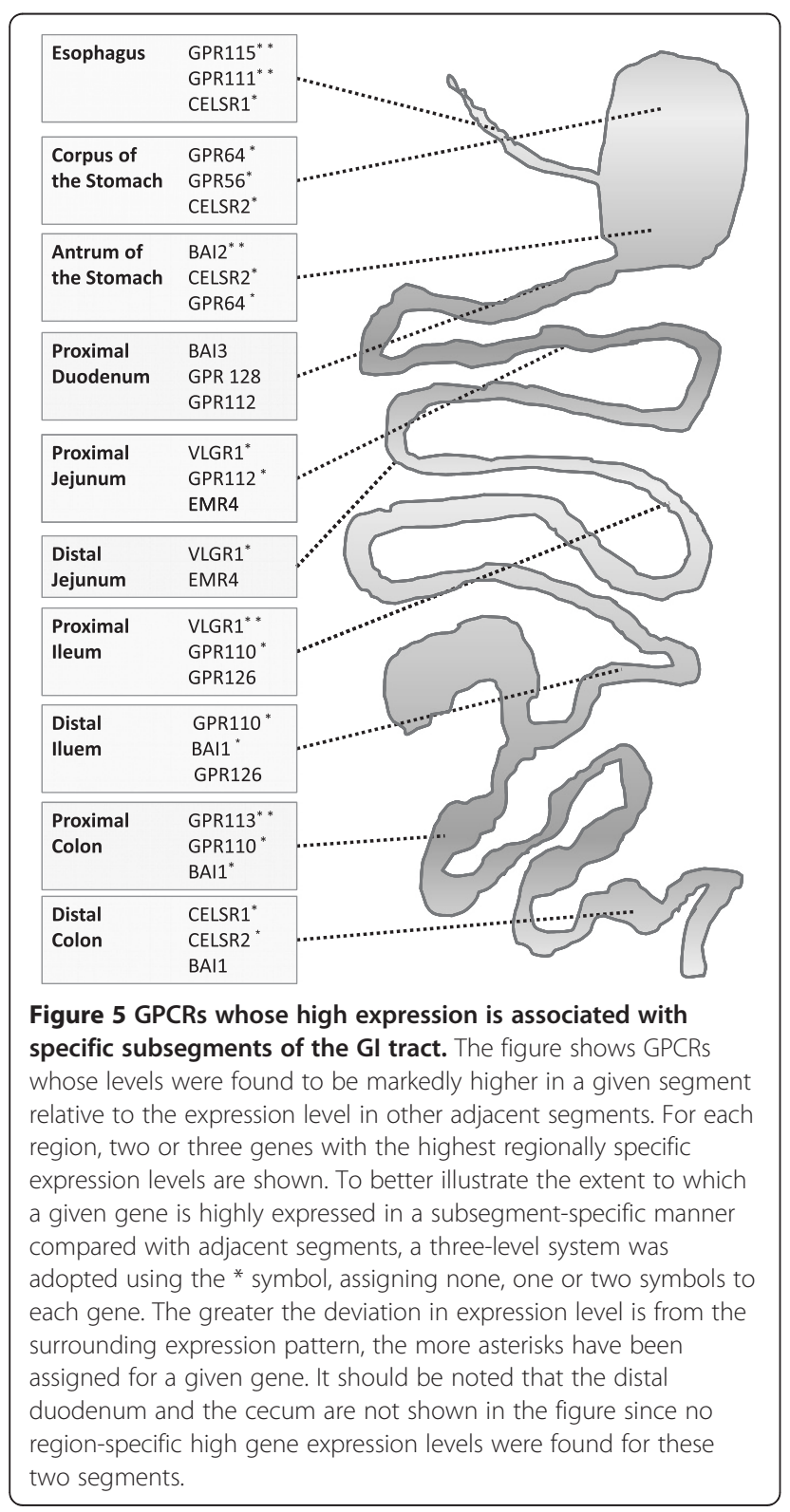

entity but taking into account proximodistal differences. It is worth noting that members of the same group, e.g. Group II members GPR114 and GPR64 or Group VII members GPR111 and GPR113, are expressed in different segments, thus they might regulate different functions.

It should be also noted that the direct comparison between our findings and previous studies may not always be possible, mainly due to the species used (mouse vs rat) and dissection differences, as other authors [35] analyzed the mucosa and muscle separately without taking into account the proximodistal subsegmentation of the GI tract. Our results are however consistent with the result previously obtained by our group [36]: genes that had been identified as being expressed along the GI tract had their expression pattern confirmed, though in greater detail. Examples of these genes include GPR133, GPR124, GPR125 and all members of Group III. In line with the earlier report, we did not detect GPR112, GPR126 or GPR128 in the stomach. Even so, there are some discrepancies, for example CELSR2 (in contrast to CELSR1) was not detected by Haitina and coworkers, whereas herein we detected both CELSR receptors, identifying a very similar pattern (Figure 3 ). This can be explained by considering that a relatively low gene expression in the GI tract relative to other tissue types could have prompted a conclusion that the expression level in the gut is negligible. Compared to the findings by Ito et al., we found no expression of either BAII or GPR126 in the upper intestine - this may be due to the different species used [35]. It should be emphasized, however, that for many other GPCRs such as BAI2, BAI3, CD97, GPR111 and GPR112, our results confirm and refine the expression patterns found by the aforementioned group. The results might have been somewhat affected by the timing of the experiments or other conditions, such as an overnight fast. Furthermore, mRNA expression does not always correspond to protein expression $[64,65]$. Finally, GPCRs are known to undergo extensive alternative splicing [3] that generates multiple transcripts including soluble forms: primers used in this study are located in the 7TM regions and thus might not cover the entire transcript population.

\section{Conclusions}

Taken together these results indicate that, compared to solute carriers, Adhesion GPCRs display more restricted expression patterns in the GI tract [29], suggesting that Adhesion GPCRs play a more specific role in the GI tract, a role that could be important both for physiological or pathological conditions. This notion is further strengthened by the fact that Adhesion GPCRs are known to be restricted to certain cell types and to be highly regulated in their expression, likely serving distinct physiological functions [6]. We should therefore consider that GPCRs 
represent an unexploited potential for drug targeting [66]. However, given that GPCRs constitute the most common drug target (36\%), but less than 82 distinct GPCRs are targeted, this clearly highlights the importance of exploring Adhesion GPCRs as potential drug targets.

In summary, our study shows that about $70 \%$ of the rat Adhesion GPCRs display a widespread or ubiquitous distribution while about a quarter of the studied receptors had limited expression in the GI tract. Their extensive distribution suggests a fundamental role of this receptor family.

\section{Additional files}

Additional file 1: Primers used for real-time PCR analysis. The table includes gene names for rat ( $r$ ) Adhesion GPCRs and house-keeping genes $\left({ }^{*}\right)$, GenBank accession numbers, primer sequences and the expected size of the PCR products. NA - not available.

Additional file 2: Summary of relative expression of all Adhesion GPCR members. Expression levels relative for each gene (maximal level of expression set to 1 ; n.d., not detected after 40 cycles of the PCR). The phylogenetic grouping is based on the 7TM regions [3]. GPR111, GPR113, GPR115 were only expressed in one sub-segment: the expression value was arbitrarily set to 1 to indicate the presence of expression. GPR133 and CELSR3 could not be detected in any segment.

\section{Competing interests}

The authors declare that they have no competing interests.

\section{Authors' contributions}

LB carried out the RT-qPCR study, performed the statistical analysis and drafted the manuscript. JC participated in the design of the study and help to draft the manuscript. PKO participated in the design of the study and help to draft the manuscript. ON carried out histological dissections and tissue preparation. AW participated in the design and coordination of the study. HBS conceived the study, and participated in its design and coordination and helped to draft the manuscript. All authors read and approved the final manuscript.

\section{Acknowledgements}

The studies were supported by the Swedish Research Council and the Novo Nordisk Foundation.

We thank Mathias Rask-Andersen who provided valuable discussion on RTqPCR analysis.

\section{Author details}

${ }^{1}$ Department of Neuroscience, Uppsala University, BMC, Uppsala SE 75124 Sweden. ${ }^{2}$ Department of Biomedical Sciences, University of Modena and Reggio Emilia, Via Campi, 41125 Modena, Italy. ${ }^{3}$ Department of Biological Sciences, University of Waikato, Hamilton, New Zealand.

Received: 17 February 2012 Accepted: 31 August 2012

Published: 25 September 2012

\section{References}

1. Lagerström MC, Schiöth HB: Structural diversity of G protein-coupled receptors and significance for drug discovery. Nat Rev Drug Discov 2008, 7(4):339-357.

2. Fredriksson R, Lagerström MC, Lundin L-G: The G-protein-coupled receptors in the human genome form five main families. Phylogenetic analysis, paralogon groups, and fingerprints. Mol Pharmacol 2003, 63(6):1256-1272.

3. Bjarnadottir TK, Fredriksson R, Schioth HB: The adhesion GPCRs: a unique family of $G$ protein-coupled receptors with important roles in both central and peripheral tissues. Cell Mol Life Sci 2007, 64(16):2104-2119.
4. Lin H-H, Chang G-W, Davies JQ, Stacey M, Harris J, Gordon S: Autocatalytic cleavage of the EMR2 receptor occurs at a conserved $\mathrm{G}$ protein-coupled receptor proteolytic site motif. J Biol Chem 2004, 279(30):31823-31832.

5. Krasnoperov V, Bittner MA, Holz RW, Chepurny O, Petrenko AG: Structural requirements for alpha-latrotoxin binding and alpha-latrotoxinstimulated secretion. A study with calcium-independent receptor of alpha-latrotoxin (CIRL) deletion mutants. J Biol Chem 1999, 274(6):3590-3596.

6. Yona S, Lin H-H, Siu WO, Gordon S, Stacey M: Adhesion-GPCRs: emerging roles for novel receptors. Trends Biochem Sci 2008, 33(10):491-500.

7. Bjarnadottir TK, Geirardsdottir K, Ingemansson M, Mirza MA, Fredriksson R, Schioth HB: Identification of novel splice variants of Adhesion G proteincoupled receptors. Gene 2007, 387(1-2):38-48.

8. Lelianova VG, Davletov BA, Sterling A, Rahman MA, Grishin EV, Totty NF, Ushkaryov YA: Alpha-latrotoxin receptor, latrophilin, is a novel member of the secretin family of $\mathrm{G}$ protein-coupled receptors. J Biol Chem 1997, 272(34):21504-21508.

9. Little KD, Hemler ME, Stipp CS: Dynamic regulation of a GPCR-tetraspanin$G$ protein complex on intact cells: central role of CD81 in facilitating GPR56-Galpha q/11 association. Mol Biol Cell 2004, 15(5):2375-2387.

10. Sanger GJ, Lee $\mathrm{K}$ : Hormones of the gut-brain axis as targets for the treatment of upper gastrointestinal disorders. Nat Rev Drug Discov 2008, 7(3):241-254.

11. Gross KJ, Pothoulakis C: Role of neuropeptides in inflammatory bowel disease. Inflamm Bowel Dis 2007, 13(7):918-932.

12. Round JL, Mazmanian SK: The gut microbiota shapes intestinal immune responses during health and disease. Nat Rev Immunol 2009, 9(5):313-323.

13. Wren AM, Bloom SR: Gut hormones and appetite control. Gastroenterology 2007, 132(6):2116-2130.

14. Konturek SJ, Konturek JW, Pawlik T, Brzozowski T: Brain-gut axis and its role in the control of food intake. J Physiol Pharmacol 2004, 55(1 Pt 2):137-154.

15. Engelstoft MS, Egerod KL, Holst B, Schwartz TW: A gut feeling for obesity: 7TM sensors on enteroendocrine cells. Cell Metab 2008, 8(6):447-449.

16. Rayasam GV, Tulasi VK, Davis JA, Bansal VS: Fatty acid receptors as new therapeutic targets for diabetes. Expert Opin Ther Targets 2007, 11(5):661-671.

17. Tazoe H, Otomo Y, Kaji I, Tanaka R, Karaki SI, Kuwahara A: Roles of shortchain fatty acids receptors, GPR41 and GPR43 on colonic functions. J Physiol Pharmacol 2008, 59(Suppl 2):251-262.

18. Zabel BA, Agace WW, Campbell JJ, Heath HM, Parent D, Roberts Al, Ebert EC, Kassam N, Qin S, Zovko M, et al: Human G protein-coupled receptor GPR-9-6/CC chemokine receptor 9 is selectively expressed on intestinal homing $T$ lymphocytes, mucosal lymphocytes, and thymocytes and is required for thymus-expressed chemokine-mediated chemotaxis. $J$ Exp Med 1999, 190(9):1241-1256.

19. Jarmin DI, Rits M, Bota D, Gerard NP, Graham GJ, Clark-Lewis I, Gerard C: Cutting edge: identification of the orphan receptor G-protein-coupled receptor 2 as CCR10, a specific receptor for the chemokine ESkine. J Immunol 2000, 164(7):3460-3464. Baltimore, Md: 1950.

20. Isensee J, Meoli L, Zazzu V, Nabzdyk C, Witt H, Soewarto D, Effertz K, Fuchs $H$, Gailus-Durner $V$, Busch D, et al: Expression pattern of $G$ protein-coupled receptor 30 in LacZ reporter mice. Endocrinology 2009, 150(4):1722-1730.

21. McClanahan T, Koseoglu S, Smith K, Grein J, Gustafson E, Black S, Kirschmeier P, Samatar AA: Identification of overexpression of orphan G protein-coupled receptor GPR49 in human colon and ovarian primary tumors. Cancer Biol Ther 2006, 5(4):419-426.

22. Wobus M, Huber O, Hamann J, Aust G: CD97 overexpression in tumor cells at the invasion front in colorectal cancer (CC) is independently regulated of the canonical Wnt pathway. Mol Carcinog 2006, 45(11):881-886.

23. Han S-L, Xu C, Wu X-L, Li J-L, Liu Z, Zeng Q-Q: The impact of expressions of CD97 and its ligand CD55 at the invasion front on prognosis of rectal adenocarcinoma. Int J Color Dis 2010, 25(6):695-702.

24. Liu D, Trojanowicz B, Radestock Y, Fu T, Hammje K, Chen L, Hoang-Vu C: Role of CD97 isoforms in gastric carcinoma. Int J Oncol 2010, 36(6):1401-1408

25. Yona S, Lin H-H, Dri P, Davies JQ, Hayhoe RPG, Lewis SM, Heinsbroek SEM, Brown KA, Perretti M, Hamann J, et al: Ligation of the adhesion-GPCR EMR2 regulates human neutrophil function. FASEB J 2008, 22(3):741-751. 
26. Guillem PG: How to make a Barrett esophagus: pathophysiology of columnar metaplasia of the esophagus. Dig Dis Sci 2005, 50(3):415-424

27. Crew KD, Neugut Al: Epidemiology of gastric cancer. World J Gastroenterol 2006, 12(3):354-362.

28. Xavier RJ, Podolsky DK: Unravelling the pathogenesis of inflammatory bowel disease. Nature 2007, 448(7152):427-434.

29. Cedernaes J, Olszewski PK, Almén MS, Stephansson O, Levine AS, Fredriksson R, Nylander O, Schiöth HB: Comprehensive analysis of localization of 78 solute carrier genes throughout the subsections of the rat gastrointestinal tract. Biochem Biophys Res Commun 2011, 411(4):702-707.

30. Sreedharan S, Shaik JHA, Olszewski PK, Levine AS, Schiöth HB, Fredriksson R: Glutamate, aspartate and nucleotide transporters in the SLC17 family form four main phylogenetic clusters: evolution and tissue expression. BMC Genomics 2010, 11:17-17.

31. Livak KJ, Schmittgen TD: Analysis of relative gene expression data using real-time quantitative PCR and the 2(-Delta Delta $C(T)$ ) Method. Methods 2001, 25(4):402-408. San Diego, Calif.

32. Vandesompele J, De Preter K, Pattyn F, Poppe B, Van Roy N, De Paepe A, Speleman F: Accurate normalization of real-time quantitative RT-PCR data by geometric averaging of multiple internal control genes. Genome Biol 2002, 3(7):RESEARCH0034-RESEARCH0034.

33. Marchler-Bauer A, Panchenko AR, Shoemaker BA, Thiessen PA, Geer LY, Bryant SH: CDD: a database of conserved domain alignments with links to domain three-dimensional structure. Nucleic Acids Res 2002, 30(1):281-283.

34. Regard JB, Sato IT, Coughlin SR: Anatomical profiling of $G$ protein-coupled receptor expression. Cell 2008, 135(3):561-571.

35. Ito J, Ito M, Nambu H, Fujikawa T, Tanaka K, Iwaasa H, Tokita S: Anatomical and histological profiling of orphan G-protein-coupled receptor expression in gastrointestinal tract of C57BL/6 J mice. Cell Tissue Res 2009, 338(2):257-269.

36. Haitina T, Olsson F, Stephansson O, Alsiö J, Roman E, Ebendal T, Schiöth HB, Fredriksson R: Expression profile of the entire family of Adhesion G protein-coupled receptors in mouse and rat. BMC Neurosci 2008, 9:43-43.

37. Chen G, Yang L, Begum S, Xu L: GPR56 is essential for testis development and male fertility in mice. Dev Dyn 2010, 239(12):3358-3367.

38. Iguchi T, Sakata K, Yoshizaki K, Tago K, Mizuno N, Itoh H: Orphan G Proteincoupled Receptor GPR56 Regulates Neural Progenitor Cell Migration via a Ga12/13 and Rho Pathway. J Biol Chem 2008, 283(21):14469-14478.

39. Koirala S, Jin Z, Piao X, Corfas G: GPR56-Regulated Granule Cell Adhesion Is Essential for Rostral Cerebellar Development. J Neurosci 2009, 29(23):7439-7449.

40. Sud N, Sharma R, Ray R, Chattopadhyay TK, Ralhan R: Differential expression of G-protein coupled receptor 56 in human esophageal squamous cell carcinoma. Cancer Lett 2006, 233(2):265-270.

41. Hamann J, Vogel B, van Schijndel GM, van Lier RA: The seven-span transmembrane receptor CD97 has a cellular ligand (CD55, DAF). J Exp Med 1996, 184(3):1185-1189.

42. Hoek RM, de Launay D, Kop EN, Yilmaz-Elis AS, Lin F, Reedquist KA, Verbeek JS, Medof ME, Tak PP, Hamann J: Deletion of either CD55 or CD97 ameliorates arthritis in mouse models. Arthritis Rheum 2010, 62(4):1036-1042

43. Visser L, de Vos AF, Hamann J, Melief MJ, van Meurs M, van Lier RA, Laman $J D$, Hintzen RQ: Expression of the EGF-TM7 receptor CD97 and its ligand CD55 (DAF) in multiple sclerosis. J Neuroimmunol 2002, 132(1-2):156-163.

44. Jaspars LH, Vos W, Aust G, Van Lier RA, Hamann J: Tissue distribution of the human CD97 EGF-TM7 receptor. Tissue Antigens 2001, 57(4):325-331.

45. Veninga $H$, Becker $S$, Hoek RM, Wobus M, Wandel $E$, van der Kaa J, van der Valk M, de Vos AF, Haase H, Owens B, et al: Analysis of CD97 expression and manipulation: antibody treatment but not gene targeting curtails granulocyte migration. J Immuno/ 2008, 181(9):6574-6583. Baltimore, Md: 1950.

46. van Hogezand RA, Witte AM, Veenendaal RA, Wagtmans MJ, Lamers CB: Proximal Crohn's disease: review of the clinicopathologic features and therapy. Inflamm Bowel Dis 2001, 7(4):328-337.

47. Danese S, Sans M, de la Motte C, Graziani C, West G, Phillips MH, Pola R, Rutella S, Willis J, Gasbarrini A, et al: Angiogenesis as a novel component of inflammatory bowel disease pathogenesis. Gastroenterology 2006, 130(7):2060-2073.

48. Koutroubakis IE, Tsiolakidou G, Karmiris K, Kouroumalis EA: Role of angiogenesis in inflammatory bowel disease. Inflamm Bowel Dis 2006, 12(6):515-523.

49. Davies B, Behnen M, Cappallo-Obermann H, Spiess A-N, Theuring F, Kirchhoff C: Novel epididymis-specific mRNAs downregulated by HE6/ Gpr64 receptor gene disruption. Mol Reprod Dev 2007, 74(5):539-553.

50. Tissir F, Qu Y, Montcouquiol M, Zhou L, Komatsu K, Shi D, Fujimori T, Labeau J, Tyteca D, Courtoy P, et al: Lack of cadherins Celsr2 and Celsr3 impairs ependymal ciliogenesis, leading to fatal hydrocephalus. Nat Neurosci 2010, 13(6):700-707.

51. Yates LL, Schnatwinkel C, Murdoch JN, Bogani D, Formstone CJ, Townsend S, Greenfield A, Niswander LA, Dean CH: The PCP genes Celsr1 and Vangl2 are required for normal lung branching morphogenesis. Hum Mol Genet 2010, 19(11):2251-2267.

52. Leja J, Essaghir A, Essand M, Wester K, Oberg K, Tötterman TH, Lloyd R Vasmatzis G, Demoulin J-B, Giandomenico V: Novel markers for enterochromaffin cells and gastrointestinal neuroendocrine carcinomas. Mod Pathol 2009, 22(2):261-272.

53. Spiller R: Serotonin and GI clinical disorders. Neuropharmacology 2008, 55(6):1072-1080.

54. Kidd M, Modlin IM, Gustafsson BI, Drozdov I, Hauso O, Pfragner R: Luminal regulation of normal and neoplastic human EC cell serotonin release is mediated by bile salts, amines, tastants, and olfactants. Am J Physiol Gastrointest Liver Physiol 2008, 295(2):G260-272

55. Kang X, Xiao X, Harata M, Bai Y, Nakazaki Y, Soda Y, Kurita R, Tanaka T, Komine $F$, lzawa $K$, et al: Antiangiogenic activity of BAl1 in vivo: implications for gene therapy of human glioblastomas. Cancer Gene Ther 2006, 13(4):385-392.

56. Das $S$, Owen KA, Ly KT, Park D, Black SG, Wilson JM, Sifri CD, Ravichandran $\mathrm{KS}$, Ernst PB, Casanova JE: Brain angiogenesis inhibitor 1 (BAI1) is a pattern recognition receptor that mediates macrophage binding and engulfment of Gram-negative bacteria. Proc Natl Acad Sci 2011, 108(5):2136-2141.

57. Oostdijk EA, de Smet AM, Kesecioglu J, Bonten MJ: The role of intestinal colonization with gram-negative bacteria as a source for intensive care unit-acquired bacteremia. Crit Care Med 2011, 39(5):961-966.

58. Peleg AY, Hooper DC: Hospital-acquired infections due to gram-negative bacteria. N Engl J Med 2010, 362(19):1804-1813.

59. Monk KR, Oshima K, Jörs S, Heller S, Talbot WS: Gpr126 is essential for peripheral nerve development and myelination in mammals. Development 2011, 138(13):2673-2680. Cambridge, England.

60. Ebermann I, Wiesen MHJ, Zrenner E, Lopez I, Pigeon R, Kohl S, Löwenheim $\mathrm{H}$, Koenekoop RK, Bolz HJ: GPR98 mutations cause Usher syndrome type 2 in males. J Med Genet 2009, 46(4):277-280.

61. Nikkila H, McMillan DR, Nunez BS, Pascoe L, Curnow KM, White PC: Sequence similarities between a novel putative $\mathrm{G}$ protein-coupled receptor and $\mathrm{Na}+/ \mathrm{Ca} 2+$ exchangers define a cation binding domain. Mol Endocrinol 2000, 14(9):1351-1364. Baltimore, Md.

62. Lum AM, Wang BB, Beck-Engeser GB, Li L, Channa N, Wabl M: Orphan receptor GPR110, an oncogene overexpressed in lung and prostate cancer. BMC Cancer 2010, 10:40-40.

63. Smedby KE, Akerman M, Hildebrand H, Glimelius B, Ekbom A, Askling J: Malignant lymphomas in coeliac disease: evidence of increased risks for lymphoma types other than enteropathy-type $T$ cell lymphoma. Gut 2005, 54(1):54-59.

64. Greenbaum D, Colangelo C, Williams K, Gerstein M: Comparing protein abundance and mRNA expression levels on a genomic scale. Genome Biol 2003, 4(9):117.

65. Kislinger T, Cox B, Kannan A, Chung C, Hu P, Ignatchenko A, Scott MS Gramolini AO, Morris Q, Hallett MT, et al: Global survey of organ and organelle protein expression in mouse: combined proteomic and transcriptomic profiling. Cell 2006, 125(1):173-186.

66. Rask-Andersen M, Almén MS, Schiöth HB: Trends in the exploitation of novel drug targets. Nat Rev Drug Discov 2011, 10(8):579-590.

doi:10.1186/1471-230X-12-134

Cite this article as: Badiali et al:: Adhesion GPCRs are widely expressed throughout the subsections of the gastrointestinal tract. BMC Gastroenterology 2012 12:134. 